\title{
Guidelines for clinical practice
}

\section{Oxytocin administration during spontaneous labor: guidelines for clinical practice. Chapter 1: Definition and characteristics of normal and abnormal labor}

\author{
Rémi Béranger ${ }^{1}$, Anne A. Chantry ${ }^{2,3}$
}

\begin{abstract}
Affiliations:
1. Inserm U1085 - IRSET, University Rennes 1, avenue du Pr. Léon Bernard, 35000 Rennes, France

2. Baudelocque Midwifery School, AP-HP, Paris Descartes University, Paris, France

3. Inserm UMR 1153, Obstetrical, Perinatal and Paediatric Epidemiology Research Team (EPOPé), Centre for Epidemiology and Statistics Sorbonne Paris Cité (CRESS), DHU Risks in Pregnancy, Paris Descartes University, Paris, France
\end{abstract}

Corresponding author:

Rémi Béranger

r.beranger26@gmail.com

Conflict of interest: The authors have no conflict of interest to report. 


\section{Summary}

Since the mid-1950s, the definitions of normal labor set forth by E. Friedman have guided obstetric practices in maternity units across the globe. But recent work is challenging these definitions, now considered too restrictive and thought to induce excessive interventionism by medical professionals. The objective of this chapter of these Clinical Practice Guidelines is to redefine the structure and duration of normal labor, as well as the criteria defining abnormal labor. Based on a systematic review of the literature, we make various recommendations. In the first place, the diagnosis of labor dystocia is inappropriate during the latent phase. The active phase of the first stage of labor begins at a cervical dilation between 5 and $6 \mathrm{~cm}$. On the other hand, a speed of dilation $<1 \mathrm{~cm} / 4 \mathrm{~h}$ at the beginning of the active phase of the first stage is considered abnormal, as is a speed $<1 \mathrm{~cm} / 2 \mathrm{~h}$ above $7 \mathrm{~cm}$ dilation. The maximum duration of the descent phase of the second stage of labor cannot be determined from the literature, but the risk-benefit balance becomes less favorable after 3 hours. Finally, the literature does not justify any recommendation about the maximum duration of the expulsion phase. These new guidelines should make it possible to reduce the rates of oxytocin use and of cesareans for labor dystocia.

Key words: pregnancy, obstetric labor, dystocia, professional guidelines 


\section{Introduction}

Since the 1950s, the labor curves compiled by Friedman have defined the diverse phases of labor and the duration considered "normal" for each of them worldwide. Most maternity units around the world have long based their intervention strategies for correcting labor that is abnormally protracted or appears arrested (labor dystocia) on Friedman's work. Nonetheless, during the past two decades, several publications have challenged the relevance of the Friedman curves [1-4], in view of trends in both population characteristics and obstetric practices that can influence the course of labor [5]. For example, since Friedman's analyses, women's age at delivery has risen, together with the proportion of obese women and infant birth weights, in France [6] and elsewhere, including the United States [5]. Similarly, some obstetric practices that may influence the duration of different phases of labor have also changed. We note in particular the rising use of induction of labor and oxytocin during labor as well as the routine practice of amniotomies and epidural analgesia (although the influence of the latter factor remains controversial in the literature).

Recent studies among more contemporary populations and using more sophisticated mathematical methods suggest that the normal duration of labor is longer than that described by Friedman [3,7]. They also call for a redefinition of the different phases of labor, insofar as too restrictive a definition of labor can result in inappropriate management (oxytocin administration, and operative vaginal and cesarean deliveries) and induce unnecessary (and thus by definition, excessive) morbidity in women and their babies. In a survey conducted at the turn of the century among North American maternity departments (Canadian, US, and Mexican), with 89 responding among the 500 contacted, 35\% no longer used the Friedman 
standards because they considered them out-of-date and $88 \%$ believed that they should be redefined [8].

In a literature review, Spong et al. (2012) described the different causes of cesareans during the first stage of labor [9]. Listed among the key points that could help to reduce the prevalence of these cesareans in the US were better definitions of failure of induction and of labor dystocia as well as better monitoring of fetal status and more frequent external cephalic version.

Our objective was to review and synthesize recent data about the normal duration of labor and the criteria required to justify intervention in labor considered abnormal. This article also deals with the definition, causes and consequences of labor dystocia.

\section{Material and methods}

This study is a review of the literature. The articles selected for our research bibliography were identified in the Medline database from the following search algorithm: "nonprogressive labor" [tiab] OR "augmented labor"[tiab] OR "labor dystocia"[tiab] OR "labour dystocia"[tiab] OR "non progressive labour"[tiab] OR "augmented labour"[tiab] OR "labor progress"[tiab] OR "labour progress"[tiab] OR "labor progression"[tiab] OR "labour progression"[tiab] OR “labor curve"[tiab] OR "labor pattern" [tiab] OR "labor patterns"[tiab] OR “labor norms" [tiab]. On October 30, 2015, this algorithm identified 473 articles, listed at the following link: http:/www.ncbi.nlm.nih.gov/sites/myncbi/18e3volUNjr5r/collections/48394990/public/. 
Our analysis covers only articles concerning human births, written in French or English, and considered relevant. Case reports, letters, and comments to editors were excluded, as were reviews of the literature that provided no new information.

The final selection of relevant articles for this analysis included several stages. First, each author read the titles and abstracts of the initial 473 articles selected by the algorithm to choose articles to be read in full $(\mathrm{n}=140)$. The authors then excluded articles that did not appear relevant on full reading. They next discussed articles selected by only one of them, one by one, until they reached a consensus. Overall, 83 of the initial 473 articles (18\%) were selected for this review. Thirty additional articles were subsequently identified through reading the 83 selected (see Figure 1).

We also consulted guidelines from various international learned societies, including the American College of Obstetricians and Gynecologists (ACOG) and the Society of Maternal and Fetal Medicine (SMFM), as well as those of the National Institute of Clinical Excellence (NICE).

When we say that something should or should not be done, we mean to say that it is a recommendation unless a specific reason based on the clinician's experience, the patient's individual characteristics, or the organization of care overrides it. Should essentially means must unless there is a strong reason not to, and should not means do not, unless there is a strong reason to do it.

\section{What are the structure and the duration of normal labor?}




\section{What is the structure of normal labor?}

The different phases of labor that have been the international reference in obstetrics for the past 60 years were defined from two samples, of 100 and then 500 women [10,11]. Presenting his observations on graph paper (duration of labor along the $\mathrm{X}$ axis and cervical dilation on the $\mathrm{Y}$ axis), Friedman described an S-shaped curve for the first stage of labor, that is, the period of cervical dilation). He distinguished two phases: one latent and the other active. The latter was itself composed of three steps (an acceleration phase, a stable one, and a decelerating one), each different in terms of their speed of dilation (LE3). Friedman also described a second stage of labor that extended from complete cervical dilation to birth of the fetus. It should be noted that the sample of 500 women was a consecutive series of nulliparas, mainly singleton pregnancies, but also 4\% twin pregnancies and one fetus in breech presentation. Most of the women entered labor spontaneously (96\%), 9\% received oxytocin, and only $8 \%$ had epidural analgesia. These results were later confirmed in the 1970 s by work conducted on a population of 10,000 women, in an early computerized analysis of labor [12].

Since the report by Zhang et al. in 2002, most of the studies questioning the current relevance of Friedman's curves have found that the speed of dilation during the active phase of the first stage is not constant and that the prolongation of the duration of labor relative to these reference data concerns mainly this first phase of labor. Although dilation speed appears to accelerate at $4-5 \mathrm{~cm}$, neither the stable phase nor the deceleration phase identified by Friedman was found among the nulliparas in Zhang's sample (1162 nulliparas admitted before $7 \mathrm{~cm}$, with singleton pregnancies, at term, in cephalic presentation and delivered vaginally)

[3] (LE2). The dilation curve followed an exponential model that did not resemble the Sshaped curve suggested by Friedman (Figure 2). 
An older study of grand multiparas ( $>5$ ) made similar observations. In a series of 500 women who gave birth in the US in 1978-1981, Petrikovsky et al. described an exponential dilation curve, with no deceleration phase and the transition from the latent to the active phase occurring around 5-6 cm [13]. They provided little information about their methods, other than that they used various "nonlinear models."

A first explanation for this discordance between curves may therefore be linked to the statistical approach used. Since Zhang et al., the principal publications have applied more appropriate and more modern analytic approaches, such as survival analysis with censored intervals to calculate the median duration of labor (overall or for each $\mathrm{cm}$ of dilation), or modeling the labor curves with polynomial functions (used to model dilation curves according to their mean). The deceleration phase described by Friedman may actually have been due to an artefact, because the examination was performed only at set regular intervals and dilation was measured only up to $10 \mathrm{~cm}$. For example, if dilation increased from 9 to $10 \mathrm{~cm}$ in 30 minutes and then stayed at full dilation for 30 minutes until the next examination, the dilation speed recorded would be $1 \mathrm{~cm}$ in an hour rather than in 30 minutes $[14,15]$.

Cohen and Friedman considered that the disappearance of this deceleration phase may have been associated not only with examinations spaced too far apart, but also with a selection bias in the studies, linked to the exclusion of cesareans during labor: the deceleration phase may have been more marked in cases with difficulties in engagement [16]. Nonetheless, Zaki et al. and Leftwich et al., who used the modern statistical techniques described above in large populations, did not identify a deceleration phase although they did not exclude cesareans from their sample [17,18]. 


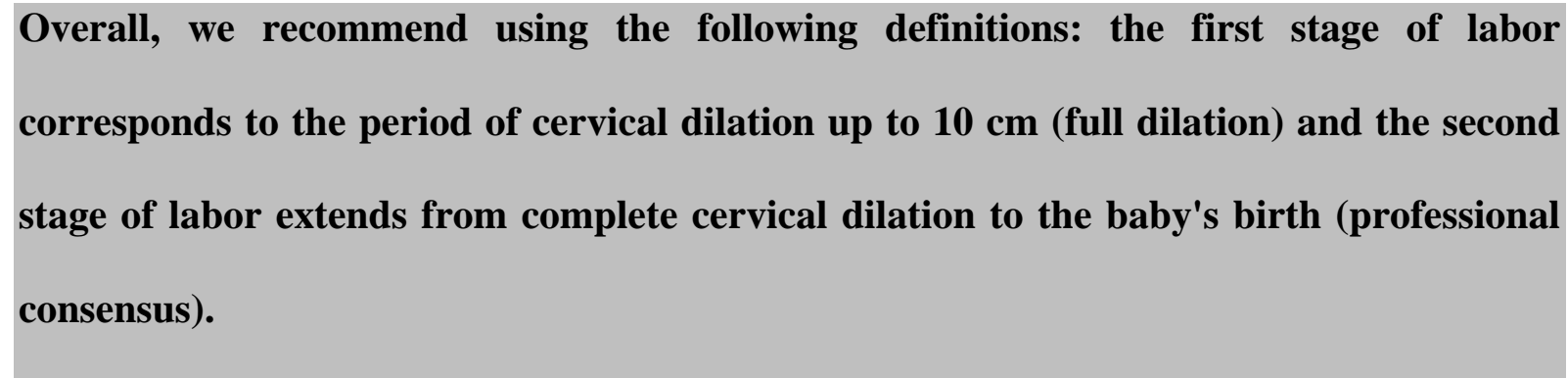

\section{$\underline{\text { The first stage of labor: latent and active phases }}$}

The beginning of the active phase is generally distinguished by an acceleration of dilation speed. Two points make it difficult to define the latent phase in the literature: first, its threshold seems to vary between women, and second, cervical dilation does nonetheless occur during this phase. The onset of labor is generally defined by the presence of painful and regular uterine contractions, associated with cervical dilation. In most studies, the threshold defining the transition between the latent and active phases is set at $4 \mathrm{~cm}$ of dilation; other studies place it at $3 \mathrm{~cm}$ instead or describe the latent phase based on the dilation speed rather than a threshold of dilation.

Peisner and Rosen, in a quite old study (1979-1982) of 1699 women in spontaneous labor with a singleton fetus in cephalic presentation (including 1060 nulliparas), showed that the threshold of transition between the latent and active phase is probably situated at a dilation $>$ $3 \mathrm{~cm}$ [19] (LE3). Relying on Friedman's definition of normal labor to define the active phase $(>1.2 \mathrm{~cm} / \mathrm{h}$ for nulliparous and $>1.5 \mathrm{~cm} / \mathrm{h}$ for parous women, including both primiparous and multiparous women), $50 \%$ of women were in the active phase at $4 \mathrm{~cm}, 74 \%$ at $5 \mathrm{~cm}$, and $89 \%$ at $6 \mathrm{~cm}$. After secondarily excluding women with protracted or stopped labor, the authors calculated that $60 \%$ were in the active phase at $4 \mathrm{~cm}$, and $89 \%$ at $5 \mathrm{~cm}$ (LE3). These results 
appeared similar in nulliparous and parous women. Some women (1\%) even gave birth without ever reaching the dilation speed threshold defining the active phase.

Laughon et al. compared data from two cohorts of women from which the speed of labor has been estimated, that is, the Collaborative Perinatal Project (CPP) and the Consortium for Safe Labor (CSL). The CPP is a multicenter prospective cohort from 12 US hospitals that collected information on the labor of 44,669 women recruited from 1959 through 1965 . The CSL is a multicenter retrospective cohort representative of the general population of US women; it covers more than 200,000 women who gave birth between 2002 and 2008 in 19 hospitals. The women in the (more recent) CSL cohort were on average significantly older, had a higher BMI, received both epidural analgesia and oxytocin during labor more often, and had longer first and second stages of labor than those in the CPP cohort [5] (LE2).

From a sample of 62,415 parturients in the CSL cohort, Zhang et al. found that the inflection point of dilation speed was around $6 \mathrm{~cm}$. They thus defined the beginning of the active phase of labor at $6 \mathrm{~cm} \mathrm{[7]} \mathrm{(LE2).}$

In a separate study reanalyzing the CPL data, Zhang et al. found an inflection point for the dilation curves that suggested that the active phase of labor begins around $5 \mathrm{~cm}$ for parous women and $5.5 \mathrm{~cm}$ for the nulliparas, although Friedman had suggested a transition around 3$4 \mathrm{~cm}$ in his work covering the same periods [20]. The closeness of the dilation curves analyzed by Zhang's group in the CSL (2004-2008) and CPP (1959-1965) data tends to show that the differences between the results of Zhang and Friedman for the 1950s are more strongly related to differences in their methods of statistical analysis than to changes in either 
population characteristics or obstetric practices. The inflection point appeared less marked for the nulliparas, probably because of their greater interindividual variability.

Nonetheless, reliance on dilation curves to define the transition between the latent and active phase can produce biased conclusions, insofar as these curves are based on mean rather than median speeds. The clinical impact nonetheless remains limited (the rest of this paragraph contains the technical explanations). There is strong variability in the $4-6 \mathrm{~cm}$ range, visible from the median data and the 95th percentiles, and due to the fact that some of these patients were not in labor (see Peisner and Rosen [19]). To the extent that the dilation speed has a leftcensored log-normal distribution (many subjects with low values and a few with much longer durations), the range of the duration probably influenced the mean dilation speed, shifting it away from the median. Concretely, this variability is probably responsible for flattening the curves by shifting the mean. When this variability is reduced, after $6 \mathrm{~cm}$, the mean catches up with the median and thus creates the impression of a point of inflection that is located at the end of the transition from latent to active labor and not at the center. Detailing the median dilation speed more precisely, centimeter by centimeter (not influenced by the minimum and maximum values), we see that it increased most rapidly around $5 \mathrm{~cm}$, rather than at $6 \mathrm{~cm}$, for both the nulliparous and parous women (Tables 1, 2 and 3). The exclusion of cesareans for dystocia may also affect this speed, if these women have protracted latency phases more frequently (some might have had cesareans because they were incorrectly considered to be in the active phase).

Overall, the latent and active phases of the first stage of labor should be differentiated (grade B). The beginning of the latent phase is defined by the presence of regular uterine contractions associated with cervical modifications (professional consensus). The active 


\section{phase begins between 5 and $6 \mathrm{~cm}$ of cervical dilation and is accompanied by regular uterine contractions (LE2).}

\section{What is the normal duration of the first stage of labor?}

According to Friedman, the latent phase lasts a mean of 8.6 hours for nulliparas and 5.3 hours for parous women, while the active phase (acceleration, stability, and decelerations) lasts respectively 4.9 and 2.2 hours. He described dilation speed as going from 1.2 to $3 \mathrm{~cm} / \mathrm{h}$ for the nulliparas and 1.5 to $5.7 \mathrm{~cm} / \mathrm{h}$ for the others [11]. These data were confirmed by a subsequent analysis of 10,293 women [12] (LE3). Friedman defined "normal" dilation speed during the active phase as greater than $1.2 \mathrm{~cm} / \mathrm{h}$, based on the mean duration of labor +2 standard deviations (SD). Following these studies, partograms and the concept of directed pushing were developed with the aim of reducing the duration of labor and limiting the frequency of cesarean for labor dystocia. The standard management became an early amniotomy associated with oxytocin administration once the dilation speed during the active phase exceeded the threshold of $1 \mathrm{~cm} / \mathrm{h}[4]$.

At the beginning of the 1990s, Perl and Hunter observed slightly different results [21]. In a retrospective series reviewing the records of 505 nulliparas who spontaneously reached the active phase of labor, defined as $3 \mathrm{~cm}$ of cervical dilation, the authors sought to assess the relevance of a threshold of $1 \mathrm{~cm} / \mathrm{h}$ for dilation speed. Overall, $21 \%$ of the nulliparas in their study did not reach this threshold dilation speed (mean speed $<1 \mathrm{~cm} / \mathrm{h}$ ) and $10 \%$ had a mean dilation speed $<0.5 \mathrm{~cm} / \mathrm{h}$. Only $7 \%$ received oxytocin. The other characteristics of this population were not known (LE3). 
In a single-center study (1991-1994) by Albers et al., the population ( $\mathrm{n}=1473)$ was restricted to women in labor without any epidural analgesia, or induction, or oxytocin, all considered factors that could slow down labor [1]. Overall, 20\% were classified in protracted labor according to Friedman's criteria. The mean duration of the active phase $(4-10 \mathrm{~cm})$ was 7.7 for nulliparas and $5.7 \mathrm{~h}$ for parous women (19.4 and 13.7 at $+2 \mathrm{SD})$. In a second single-center study of 2511 women who gave birth in 1996 without either an epidural or oxytocin during labor, Albers found a very similar mean duration of the active phase: 7.7 hours for the nulliparas and 5.6 for the parous women (17.5 and 13.8 at $+2 \mathrm{SD})$ [22]. Jones et al., in an exclusively Hispanic population (240 women who gave birth between 1995 and 1998 in New York, found a slightly shorter active phase, but it always remained longer than the duration proposed by Friedman: 6.2 hours for nulliparas and 4.4 for the others (13.4 and 11.6 at +2 SD) [23]. Nonetheless, the analyses included only women with cervical dilation $<4 \mathrm{~cm}$ on arrival at the maternity ward. Excluding the women with more advanced dilation on arrival at the maternity ward (women with a potentially faster dilation speed) can result in overestimating the duration of labor.

Inversely, Kilpatrick et al. reported a mean duration for the first stage of labor (without distinguishing between the latent and active phases) shorter than in Friedman's series, in a population of 6991 US women (1976-1987, single-center study) [24]. In the absence of epidural analgesia, the mean duration was 8.1 hours for nulliparas in the first stage of labor (latent and active phases combined) and 5.7 hours for parous women (16.6 and 12.5 at +2 SD), while women with epidurals had mean durations respectively of 10.2 and 7.4 hours (19.0 and 14.9 at +2 SD). In a single-center study (1991-1996) limited to a population of 1006 recent Chinese immigrants to the USA, Sills et al. reported a mean duration for the first stage 
of labor of 5.4 hours (+2 SD: $11.6 \mathrm{~h}$ ), in the absence of epidural analgesia, oxytocin, and prostaglandins [25].

Zhang et al. used data from 1162 women with a vaginal delivery between 1992 and 1996 in a level-3 hospital to propose new standards for a normal dilation speed for nulliparas [3]. The mean duration of labor in that study was again longer than that reported by Friedman $(5.5 \mathrm{~h}$ vs $2.5 \mathrm{~h}$ for dilation of 4 to $10 \mathrm{~cm}$ ). In a study of 1119 nulliparas, Incerti et al. reported similar results, with a median duration of $5.5 \mathrm{~h}$ (95th percentile: $12.5 \mathrm{~h}$ ) for the active phase of the first stage of labor (4 to $10 \mathrm{~cm})$, for a mean dilation speed of approximately $1.5 \mathrm{~cm} / \mathrm{h}(95 \mathrm{th}$ percentile: $0.5 \mathrm{~cm} / \mathrm{h})[26]$.

Among a selection of 62,415 women in the CSL database, Zhang et al. found a similar median duration of dilation for nulliparous and parous women before $6 \mathrm{~cm}$ dilation, but it accelerated for the latter above this threshold (Table 1, Figure 3) [7].

Note that the strong selection of the populations in the studies of Zhang et al. does limit the generalizability of their results. The women are young (mean age 23-24 years for nulliparas and 27-30 years for the others) and represent essentially a particular subpopulation of women at low obstetric risk (cephalic presentation, at term, without induction). These methodological choices can have important consequences on the population's dilation speed. Tables 2 and 3 present the duration of dilation reported by different studies, all conducted in the same population (Consortium of Safe Labor, 2002-2008), but with different selection criteria. We note in particular that labor was slower when they included women with cesareans, inductions of labor, and preterm births, or when specific adjustments were made to the population. Similarly, it must be remembered that these cohorts report data collected in hospitals that 
applied protocols based on Friedman's work. The women with longer labor were therefore more likely to have had cesareans during labor. Accordingly, data for the longer labors are truncated, which resulted in underestimating the mean and median durations of labor, as well as the dilation speed (especially when cesareans are excluded). Excluding cesareans performed for labor dystocia from descriptions of the duration of labor for "normal" women is debatable under these circumstances.

Few studies describe the duration of the latent phase. Moreover, they generally describe the mean duration since arrival at the maternity ward and not since onset of the latent phase. They do so because as a general rule, it is difficult to determine the duration of this latent phase, especially as women arrive at the hospital at different, and sometimes advanced, stages of dilation, so that it is difficult to estimate precisely when cervical modification began.

Overall, the duration of the first stage of labor differs according to parity and is longer in nulliparas (LE2). Sufficient data to determine the normal duration of the latent phase are not currently available. The median duration of the active phase (from 5 to $10 \mathrm{~cm}$ ) of the first stage has not been defined for normal labor. Available data reporting a median duration of the progression of cervical dilation between 4 and $10 \mathrm{~cm}$ estimate it at 5.5 hours for nulliparas and 3 hours for the others (LE2).

\section{What are the structure and duration of the second stage of normal labor?}

The second stage of labor extends from full cervical dilation to expulsion (birth) of the fetus. It is essential to distinguish here the practices in North America and in France. The former 
generally begin "immediate pushing" at complete cervical dilation and consider the second stage to begin then and extend through a single phase to the child's birth. In France, where "delayed pushing" is practiced, the second stage includes a (passive) descent phase through the birth canal and an expulsion phase, with active descent of the fetus due to maternal pushing. The data from the literature are thus based on two sets of studies: those conducted in North America, which examine principally the duration of the second stage of labor as a whole, without distinguishing between the descent and expulsion phases, and several studies performed in France that focus more especially on the duration of the expulsive efforts.

\section{Second stage of labor: immediate pushing vs delayed pushing}

Around the turn of this century, several randomized controlled trials studied the effect of immediate compared with delayed pushing. The PEOPLE trial in Canada, which included more than 1800 nulliparas, is one of the largest on this topic [27]. The group of women with delayed pushing (waiting $\geq 2 \mathrm{~h}$ after full dilation) had a longer median duration of the second stage of labor than the group with early pushing (187 vs $123 \mathrm{~min}, P<0.001$ ), but a shorter median duration of expulsive efforts $(68$ vs $110 \mathrm{~min}, P<0.001)$ and fewer instrumental or cesarean deliveries (relative risk (RR) 0.79, 95\% confidence interval (CI): 0.66-0.95) (LE1). Inversely, in a trial of 178 nulliparas, delayed pushing (here a delay of $1 \mathrm{~h}$ ) did not show any advantages in terms of mode of delivery, neonatal outcome, or perineal outcome (all $P>0.05$ ) [28]. Vause et al. reported similar results for 135 nulliparas [29]. Nonetheless, these two studies probably lacked the power to identify these types of morbidity.

Four meta-analyses have compiled the data from randomized trials comparing early or immediate (at the beginning of the second stage, i.e., at full dilation) with delayed pushing. For Menez-Orieux et al. and Tuuli et al., the probability of spontaneous vaginal compared 
with operative vaginal or cesarean delivery was significantly higher in the women with delayed pushing (respectively, RR 1.09, 95\% CI 1.01-1.17) and RR 1.09, 95\% CI 1.03-1.15) [30,31] (LE3). For Roberts et al., delayed pushing was associated with a lower frequency of rotational or high forceps (RR $0.69,95 \% \mathrm{CI}: 0.55-0.87$ ), but had no statistically significant effect on the risk of cesarean (RR 0.77, 95\% CI: 0.55-1.08) [32] (LE3). The meta-analysis of Boog et al. found that neither method was superior to the other for perineal outcomes. Finally, Lemos et al. analyzed 13 studies and did not find either method superior to the other, for either mother or baby [33].

In summary, the data from the literature do not clearly show that either of these approaches is superior to the other (LE3).

\section{Data on the second-stage duration with early pushing}

In his work on 500 white women during the 1950 s, Friedman reported that the mean duration of the second stage of labor was $57 \pm 0.8$ minutes. In the 1980 s, Kilpatrick et al. studied the duration of the entire second stage in a population of 6991 women among whom this duration was not limited [24]. This absence of obstetric intervention makes this study a useful model for studying the real normal duration of the second stage. In the absence of epidural analgesia, the authors reported a mean second-stage duration of 54 minutes in nulliparas and 19 minutes in parous women (+2 SD: 132 and 61 min respectively). Among women with epidural analgesia, the mean duration was 79 minutes for the nulliparas and 45 minutes for the others (+2 SD: 185 and 131) (LE2). Albers et al. found a similar median second-stage duration without epidural analgesia, induction, or oxytocin augmented labor: 53 minutes for the nulliparas and 17 minutes for parous women (+2 SD: 147 and $57 \mathrm{~min}$ ) [1] (LE2). Similar results were also observed by Jones et al. with a mean duration of 54 minutes for nulliparas 
and 22 minutes for the others (+2 SD: 140 and $77 \mathrm{~min}$ ), but they provided no information about epidural use [23]. Finally, in a single-center series of 15,759 nulliparas (1976-2001) in California, Cheng et al. found one nullipara in five (18\%) had a second-stage duration $>3$ hours [34].

The most recent work from the CSL (Tables 2 and 3) also detailed the duration of the second stage according to different population selection criteria, with and without epidural analgesia. Without epidural analgesia, the median duration was around 40 minutes for nulliparous and 10-15 minutes for parous women (95th percentile: approximately $2-3 \mathrm{~h}$ and $1 \mathrm{~h}$, respectively) (LE2). With epidurals, this median duration extended to approximately 1 hour for nulliparas, and 20-25 minutes for parous women (95th percentile: 3-3.5 h and 1-2 h) (LE2). We must nonetheless recall that the US guidelines then in effect recommended that this stage not exceed 3 hours for nulliparas and 2 hours for other women.

Nonetheless, overall, these studies do not distinguish between the descent phase and the final delivery phase, in view of the practices that encourage pushing to begin at full dilation. Moreover, given the long interval between digital cervical examinations (generally every $2 \mathrm{~h}$ ), the time spent at full dilation is probably underestimated.

\section{Data on duration of the second stage of labor with delayed pushing (France)}

The literature includes the results of secondary analyses of two French randomized trials PREMODA (3330 women from the control group, with singleton term pregnancies at low obstetric risk, from 138 maternity units in 2001-2002) and Pithagore 6 (analysis of data for 4000 nulliparas with a vaginal delivery in 106 maternity units in 2004-2006) [35,36]. In the PREMODA trial, the median duration of the descent phase was 30 minutes (interquartile 
range, IQR $10-60$ ) and $90 \%$ of the women had a descent phase $<120$ minutes (note that $62 \%$ received oxytocin during labor) [35] (LE2). In both studies, the median duration of the expulsion phase for nulliparas ranged from 18 (IQR: 10-27) to 23 minutes (IQR: 14-32). This duration was $<40$ minutes for nearly $90 \%$ (LE2).

These results are consistent with those from data from the French AUDIPOG perinatal network (200,000 women between 2008 and 2011, unpublished data). Overall, $95 \%$ of the women had a descent phase lasting $<120$ minutes (130 for the nulliparous and 100 for the parous women) and an expulsion phase $<40$ minutes (45 and 26, respectively).

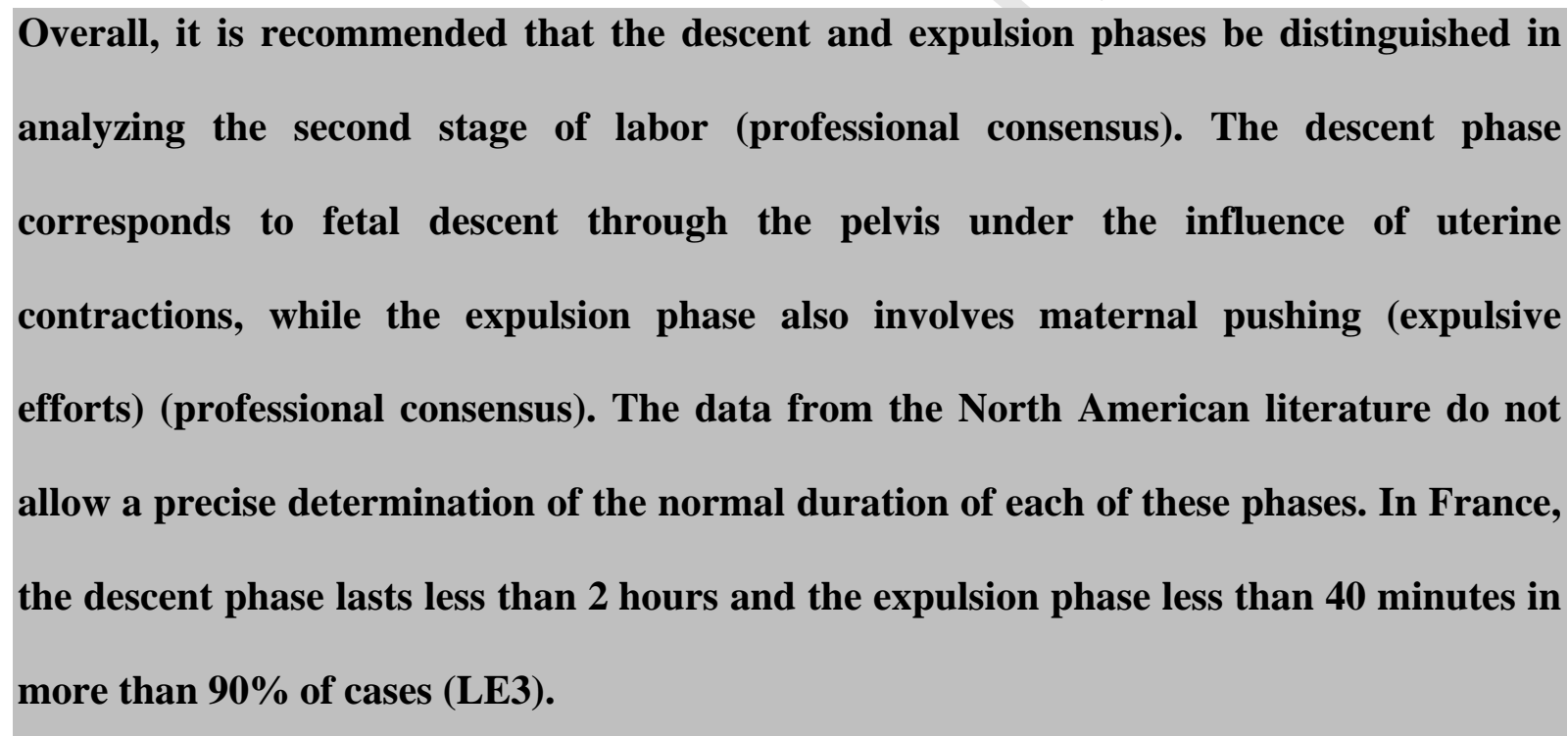

\section{What factors may influence the duration of labor?}

The results and discussions of these different points are presented elsewhere [37]. 
Overall, some factors are likely to modulate the duration of labor. The latent phase appears to be prolonged in the case of maternal obesity. Inversely, preterm delivery is associated with a shorter latent phase (LE2). Twinning and some hypertensive disorders are associated with a prolongation of the active phase of the first stage of labor (by up to 2 h) (LE2).

\section{Dynamic characteristics of abnormal labor}

Table 4 summarizes the principal individual risk factors for labor dystocia identified in the literature. The results and discussions of these different points are detailed elsewhere [37]. The effects of professional practices on the duration of labor are discussed in two other texts $[38,39]$. 


\section{The first stage of labor}

Labor dystocia is generally defined as a labor that is abnormally long or as interruption of cervical dilation (for a duration that varies between definitions). It can be mechanical or dynamic: mechanical dystocia is associated with a defect in the fit of the descending fetus or feto-pelvic disproportion; dynamic dystocia, which is one form of what is more generally referred to in English-speaking countries as labor dystocia, is associated with a defect in the intensity, frequency, or duration of uterine contractions. The distinction is not always obvious either clinically or in the literature. Accordingly, for this section, when the studies do not specify the type of dystocia, we use the generic term "dystocia" to characterize a general defect or problem in rate of progress per centimeter of cervical dilation.

As Neal et al. explained, the threshold of $<1.2 \mathrm{~cm} / \mathrm{h}$ proposed by Friedman was based only on the stable phase (that is, the phase with the maximum slope), and not on the entire active phase (acceleration, stability, and deceleration phases) [4]. According to these studies, applying the median +2 SD for these three phases together appears to produce a threshold on the order of $0.6 \mathrm{~cm} / \mathrm{h}$. Neal et al. also calculated the mean dilation speed during the active phase for the populations studied by Albers et al. [1], Albers [22], and Jones et al. [23]. The mean dilation speed in these studies varied from 0.8 to $1 \mathrm{~cm} / \mathrm{h}$ and the mean speed at $+2 \mathrm{SD}$ from 0.3 to $0.5 \mathrm{~cm} / \mathrm{h}$. Nonetheless, considering that the dilation speed is not linear and that it tends to increase as labor progresses, the authors suggest a norm $<0.5 \mathrm{~cm} / \mathrm{h}$ at the beginning of the active phase and $>0.5 \mathrm{~cm} / \mathrm{h}$ at its end. They argue that continued application of a threshold dilation speed of $1 \mathrm{~cm} / \mathrm{h}$ creates a risk of overdiagnosis of dystocia. 
Zhang et al. also underlined the nonlinear nature of labor and reported that dilation of 0.25 $\mathrm{cm} / \mathrm{h}$ before $6 \mathrm{~cm}$ was frequent $(<95$ th percentile) for nulliparas, while dilation of $0.5 \mathrm{~cm} / \mathrm{h}$ exceeded the 95 th percentile after $6 \mathrm{~cm}$, for both nulliparous and parous women $[7,20]$. Based on these data, the authors suggest that the concept of normal labor should be adjusted as labor advances and that dilation speed $<1 \mathrm{~cm} / 4 \mathrm{~h}$ should be considered abnormal before $6 \mathrm{~cm}$ dilation [7].

Rouse et al. studied a population of 542 women with arrest of progress in dilation, defined as dilation $>4 \mathrm{~cm}$ and unchanged for more than 2 hours [2]. In their study, arrest continued for $27 \%$ of the nulliparous and $18 \%$ of the parous women 2 hours after oxytocin administration, compared with only $9 \%$ and $6 \% 4$ hours after oxytocin administration. The authors thus recommend that if dilation stops progressing the duration of the perfusion should be extended to 4 hours rather than 2 , before recourse to cesarean delivery. Nonetheless, according to Peisner et al., 50\% of women are still in the latent phase at $4 \mathrm{~cm}$ of dilation [19]. The effect observed might therefore be linked to progression into the active phase, and not to an effect of oxytocin administration. The absence of a control group prevents us from ruling out this bias.

In developing countries, where medical care and access to cesarean deliveries are much more limited, the consequences of labor dystocia can be severe for mother and child. A prospective study of 266,723 women living in 6 countries with a low to intermediate level of income (Argentina, Guatemala, India, Kenya, Pakistan, and Zambia in 2010-2013) showed that the risk of maternal death within 42 days of giving birth doubles for women with labor dystocia (RR 1.9, 95\% CI 1.4-2.4) [40]. The authors also showed an excess risk of maternal (RR 1.8, 95\% CI 1.5-2.2) and fetal (RR 1.2, 95\% CI 1.1-1.3) infection and postpartum hemorrhage (PPH) (RR 2.4, 95\% CI 1.8-3.3) (LE3). These data must of course be related to the care 
capacity of the countries concerned and cannot be applied directly to France. They nonetheless help to justify the focus on the diagnosis of labor dystocia.

Various studies have looked at the impact of dystocia during the first stage of labor on maternal and fetal morbidity in the most industrialized countries. Based on a case-control study (311 cases of dystocia and 1169 controls) in Sweden in 2000-2001, Selin et al. (2008) reported an excess risk of severe PPH (> $1000 \mathrm{~mL})(\mathrm{OR} 1.9,95 \%$ CI 1.2-3.1) and of thirdand fourth-degree perineal lesions (OR 2.9, 95\% CI 1.6-5.2) associated with labor dystocia [41]. Both trends persisted after adjustment for parity, birth weight, and epidural analgesia, although they were no longer statistically significant (OR 1.5, 95\% CI 0.9-2.4 and 1.6 95\% CI 0.8-3.0, respectively) (LE3). Data from the French Pithagore 6 study also suggest an association between the duration of the active phase of the first stage of labor and the risk of PPH. The proportion of woman with an active phase $>6$ hours rose from $20.2 \%$ in the control subjects ( $\mathrm{n}=2414)$ to $34.3 \%$ in those with PPH $(\mathrm{n}=9364)$ and $38.1 \%$ in those with severe PPH (n=2494; $P<0.001$ ) [42]. An Israeli study of 240,189 women who gave birth between 1988 and 2009 showed a higher prevalence of labor dystocia in the 138 women with uterine rupture than with other women (in the first stage of labor: $9.4 \%$ vs $1.8 \%$, OR 5.7, 95\% CI 3.2-10.0; in the second stage: $13 \%$ vs $1.6 \%$, OR $9.5,95 \%$ CI 5.8-15.6) [43]. Nonetheless, the lack of statistical adjustment prevents ruling out potential confounding factors, and the definition of labor dystocia was not specified (LE4). Harper et al. looked at neonatal outcomes in a population of 5388 American women in a single-center study that took place from 2004 to 2008) [44]. Those with a duration of labor $>90$ th percentile had a higher proportion of infants transferred to neonatal special care units $(\mathrm{OR} \sim 2.5 ; P<0.01)$. 
Overall, the data from the literature do not allow us to define a normal duration for the latent phase of the first stage of labor. The threshold between the latent and the active phase varies from woman to woman (LE2). The progression of dilation from one centimeter to the next is not constant during the active phase (LE2). To define dynamic dystocia, the duration since the last cervical modification should be considered rather than total duration since the onset of labor (grade B), regardless of uterine activity.

Labor dystocia should not be diagnosed before $5-6 \mathrm{~cm}$ of cervical dilation, that is, before the end of the latent phase of the first stage of labor (professional consensus). Consequently, the term "early labor dystocia" (in French, dystocie de démarrage) should no longer be used (professional consensus). Dilation speed should be considered abnormal if it is slower than $1 \mathrm{~cm} / 4 \mathrm{~h}$ at the beginning of the active phase of the first stage and less than $1 \mathrm{~cm} / 2 \mathrm{~h}$ after $7 \mathrm{~cm}$ of dilation (Grade B).

\section{Second stage of labor}

Here again, studies conducted in North America (and practicing immediate pushing) should be distinguished from French (delayed pushing) studies.

\section{Consequences of a prolonged second stage of labor in North American practices}

Allen et al. reported one of the largest series on maternal-fetal morbidity associated with the duration of the second stage of labor; it included a population of 129,517 Canadian women who gave birth between 1988 and 2006 [45]. In nulliparas, the authors found a statistically significant and gradual (after adjustment) increase in the risk of maternal (chorioamnionitis, 
$\mathrm{PPH}$, and respiratory distress) and neonatal (transfer to neonatal special or intensive care) complications when the duration of the second stage of labor exceeded 2 hours. In parous women, a significant excess risk of both maternal (obstetric injuries, $\mathrm{PPH}$, and fever) and neonatal (respiratory distress, 5-min Apgar score $<7$ and transfer to neonatal special or intensive care) complications appeared with second-stage durations $>1$ hour. Although some associations persisted after adjustment for various confounding factors, the doseresponse effect disappeared in parous women. In this study, $14.8 \%$ of the nulliparas had a second stage of labor $>3 \mathrm{~h}$ and $3.2 \%$ of the others a second stage $>2$ hours (LE2).

The study by Cheng et al. of 15,759 Californian nulliparas also indicated a gradual increase in the risk of $\mathrm{PPH}$ with the duration of the second stage, with rates rising from $7.1 \%(0-1 \mathrm{~h})$ to $30.9 \%(>4 \mathrm{~h}$ ) [34]. After adjustment for mode of delivery and episiotomy, the relation reached statistical significance when the second stage $>3$ hours (adjusted OR 1.48, 95\% CI 1.24-1.78). A similar trend was observed for third- and fourth-degree perineal lacerations and chorioamnionitis. On the other hand, the incidence of neonatal morbidity did not increase (LE2). A subsequent study of 5,158 multiparas observed a clearly higher cesarean rate once the second stage of labor $>3$ hours (1.3-7.5\% before $3 \mathrm{~h}$; $26.3 \%$ after $3 \mathrm{~h}$ ) [46]. Similarly, the rate of operative vaginal delivery rose substantially after 2 hours (from $5-10 \%$ to $>30 \%$ ). The rates of PPH and chorioamnionitis grew gradually for each additional hour (for PPH: 13.5\% for $0-1 \mathrm{~h}, 16.7 \%$ for $1-2 \mathrm{~h}, 23.3 \%$ for $2-3 \mathrm{~h}$, and $34.1 \%$ for $\geq 3 \mathrm{~h}$; for chorioamnionitis: $2.5 \%$, $4.6 \%, 14.2 \%$, and $23 \%$ respectively). For the newborns, the frequency of an arterial $\mathrm{pH}<7$, Apgar score $<7$, and transfer to the neonatal intensive care units tended to increase when the second stage of labor exceeded 2 hours, but not consistently (LE2). In a study of 4126 American nulliparas, the proportion of vaginal deliveries fell drastically (cesarean rate of 13, 38,48 , and $70 \%$ for a second stage of $2-3 \mathrm{~h}, 3-4 \mathrm{~h}, 4-5 \mathrm{~h}$, and $\geq 5 \mathrm{~h}$, respectively), while for 
each additional hour, the risk of chorioamnionitis increased by $60 \%$ (OR adjusted for mode of delivery $=1.60,95 \%$ CI 1.40-1.83), uterine atony by $31 \%$ (ORa $1.31,95 \%$ CI $1.14-1.51)$, and third and fourth-degree perineal lacerations by $44 \%$ (ORa 1.44, 95\% CI 1.29-1.60) [47]. No notable excess risk was found for the fetus (LE2). The Canadian PEOPLE trial $(1,800$ nulliparas with singleton pregnancies, at term) reported an excess risk of PPH when the duration of active pushing exceeded $3 \mathrm{~h}$ (reference $<1 \mathrm{~h}$; ORa 2.5, 95\% CI 1.4-4.1). On the other hand, no excess risk of severe (third- and fourth-degree) perineal lesions or neonatal complications was associated with a longer duration of expulsive efforts [48] (LE3).

To our knowledge, the literature includes only one randomized trial on the subject, conducted in a US maternity ward in 2014-2015 [49]. In this trial, the 78 women had a descent period lasting as long as 1 hour, during which they were offered delayed pushing. Women allocated to the "usual care" group $(\mathrm{n}=37)$ then had $2 \mathrm{~h}$ of delayed pushing if they had epidural analgesia (and $1 \mathrm{~h}$ for those without it); those allocated to the extended care $(\mathrm{n}=41)$ had an additional hour of pushing ( $3 \mathrm{~h}$ for women with and $2 \mathrm{~h}$ for those without epidurals). Although these results must be considered with prudence in view of the absence of blinding, lack of power, and probable bias (due to posterior positions), they nonetheless indicate a lower risk of cesarean for the women with delayed pushing (RR 0.45, 95\% CI 0.22-0.93), with no excess risk of maternal or neonatal complications (maternal infection, perineal lesions, and PPH, neonatal outcomes) (LE3).

At least two studies have suggested an increased risk of shoulder dystocia in cases with an extended second stage of labor. The first examined a population of 240,000 Israeli women who gave birth between 1988 and 2010 and found an increased risk (OR 2.4, 95\% CI 1.5-3.7) after adjustment for various factors including macrosomia and maternal obesity, but not for 
duration of labor [50]. Despite the excess risk, the prevalence of shoulder dystocia in women with a prolonged second stage remained low, at 4.9\% (LE3). Mehta et al. reported similar results in a more modest case-control study conducted in the US between 1996 and 2001 (65 nulliparas with shoulder dystocia/65 controls) [51] (LE3). Although the causal link between dystocia (failure to progress) during the second stage of labor and shoulder dystocia remains questionable, the clinical association is clear, and a prolonged second stage may potentially be interpreted as a warning sign of shoulder dystocia.

Finally, a literature review of observational studies reported that a protracted second stage of labor is associated with excess maternal risks of infection and hemorrhage, but not with excess neonatal morbidity (defined by either 5-min Apgar score or transfer for neonatal care) [52]. Nonetheless, in a recent article, Leveno et al. noted that the studies that failed to show any excess risks of neonatal complications in the case of a prolonged second stage had generally adjusted their results for mode of delivery (cesarean or vaginal delivery), contrary to the studies that have identified an excess neonatal risk [53]. These authors note that cesareans are often performed because of fetal heart rate (FHR) changes, to prevent the risk of neonatal asphyxia, and therefore that adjustment for mode of delivery essentially results in underestimating unfavorable neonatal outcome.

\section{Consequences of a prolonged second stage of labor in French practices}

In a study conducted in 2004-2005 at the maternity ward of the University of Tours Hospital (1,191 nulliparas), Naime-Alix et al. reported that the frequency of PPH increased when the second stage of labor grew longer ( $>3 \mathrm{~h}$ vs $<1 \mathrm{~h}$ : $14.8 \%$ vs $4.1 \%$; $P<0.001$ ) [54]. They found similar results for chorioamnionitis $(3.1 \%$ vs $1.2 \%, P=0.01)$. More globally, an excess risk of maternal morbidity (PPH, chorioamnionitis, and third- and fourth-degree perineal lacerations) 
was shown for each additional hour of second-stage labor (ORa 1.78, 95\% CI 1.59-1.97). These analyses were adjusted for maternal BMI and age, birth weight, and duration of labor. On the other hand, no excess risk of neonatal complications was observed (LE3).

The secondary analysis of the PREMODA trial data, described above, also showed an excess risk of severe PPH $(>1000 \mathrm{~mL})$ for nulliparas in the case of prolonged pushing $(14.3 \%$ severe $\mathrm{PPH}$ in the group with "50 minutes or more" vs $1.2 \%$ in the "less than 10 min" group: ORa $10.6,95 \%$ CI 2.8-40.3). On the other hand, a prolonged descent phase was no longer at risk of severe PPH (2.3\% for a duration $>2 \mathrm{~h}$ vs $1.9 \%$ for $<1 \mathrm{~h}$ : crude OR $1.2,95 \%$ CI 0.5-2.9) [55]. No excess risk of unfavorable neonatal outcome was reported in the women with prolonged pushing [56]. The secondary analysis of the data from the PITHAGORE 6 trial (presented above) confirms these results; they show an excess risk of severe PPH in nulliparas for the group with expulsive efforts $>37$ min compared with the group with expulsive efforts $\leq 37$ $\min (\mathrm{ORa} 1.59,95 \%$ CI 1.06-2.39). The association was close to significance for all PPH (OR 1.39, 95\% CI 0.99-1.96) [36]. In this study, oxytocin administration, operative vaginal delivery, and episiotomy were also associated with an increased risk of severe PPH.

In a recent report, Korb et al. compared women who pushed for more than $45 \min (n=124)$ with those who had an operative vaginal delivery before 45 minutes for failure of labor to progress (and no FHR-related indication) (n=95) [57]. This study took place in 2013 in a Parisian maternity unit that applied no time limit to pushing and compared two groups with similar general characteristics. Nulliparas accounted for $91 \%$ of this population. In the group that pushed $>45$ minutes, $61 \%$ of the women finally had spontaneous vaginal deliveries. Women with an operative vaginal delivery for nonprogression $<45$ minutes had a much higher risk of third- and fourth-degree perineal lacerations than the others (ORa 6.5, 95\% CI 
1.1-40.1) (LE3). These analyses were adjusted for the duration of labor before $5 \mathrm{~cm}$, the time to full dilation and onset of expulsive efforts, episiotomy, manual rotation, and birth weight. An indication bias could not be totally excluded.

In summary, most of the data found in the international literature appear to report an excess risk of maternal complications (principally chorioamnionitis and $\mathrm{PPH}$ ) when the duration of the second stage of labor $>3$ hours in nulliparas and 2 hours in others. Results about the effect of this duration on neonatal outcome are divergent, and most studies have found no statistically significant associations. The studies conducted in France report results predominantly similar to those of the other international studies. Nonetheless, for PPH, the French data tend to suggest a potential excess risk that appears to be more specifically associated to the expulsive phase (ranging from more than 37 to $50 \mathrm{~min}$, depending on the study).

Generally, the absence or slightness of an excess risk of fetal/neonatal morbidity in the studies of a prolonged second stage of labor can be explained by conditions enabling effective monitoring that enable immediate intervention at the least sign of hypoxia. Women are only allowed to continue laboring as long as their fetuses have a satisfactory heart rhythm; the more fragile fetuses are delivered rapidly. This situation artificially increases the frequency of fetal morbidity in the groups of women with shorter labor.

Finally, although giving parturients more time during the second stage of labor reduces the number of cesareans (and their associated maternal-fetal risk) by allowing more women to have vaginal deliveries, the probability of vaginal delivery diminishes gradually with time, at the same time as maternal risk rises. Nonetheless, the current data in the literature do not 
allow us to identify a clear limit to the duration of the second stage of labor at which point the global risk makes cesarean delivery preferable to expectant management.

Overall, extension of the second stage of labor appears to be associated with excess maternal risk. As long as fetal monitoring is appropriate, neonatal risk does not appear to increase (LE2).

The current data do not justify setting a firm second-stage time limit that should not be exceeded, but maternal risks do increase especially from 3 hours onward. The current data do not allow the recommendation of a maximum duration to be recommended for the active pushing phase.

\section{What are the guidelines abroad?}

Synthesis of the Guidelines of the American College of Obstetricians and Gynecologists (2014):

In 2014, the American College of Obstetricians and Gynecologists and the (American) Society of Maternal-Fetal Medicine (SMFM) jointly recommended a definition of labor divided into 2 stages, with the first stage subdivided into a latent (or passive) phase and an active phase [58]. This consensus statement does not propose time thresholds to define protracted or arrested labor, but it does suggest that neither can be diagnosed before $6 \mathrm{~cm}$ of dilation, considered to be the beginning of the active phase of the first stage. Dilation that stops before $6 \mathrm{~cm}$ must not be an indication for a cesarean, nor is labor that is progressing, but slowly. It is suggested that cesareans be limited to women with no progress after $4 \mathrm{~h}$ of oxytocin, if uterine activity is satisfactory and the amniotic sac ruptured, or after $6 \mathrm{~h}$ of 
oxytocin without adequate uterine activity and no change in dilation. Before a diagnosis of lack of progress during the second stage, it is appropriate to authorize (if maternal and fetal conditions permit) 2 hours of pushing for parous and 3 hours for nulliparous women. Extension of this period may be envisioned on a case-by-case basis when appropriate (for all of these elements, the recommendations are strong, and the quality of evidence moderate).

\section{Conclusion}

Recent studies show clearly that the definitions developed by Friedman in the 1950s are inappropriate today and can lead to excessive and potentially iatrogenic interventionism by obstetrics professionals. This change is explained simultaneously by trends in population characteristics and in professional practices, but also by the use of more appropriate statistical tools for constructing curves. Analysis of the data from the literature allows us to recommend new definitions of normal labor as well as new criteria for characterizing labor as dystocic. The implementation of these guidelines should enable us to reduce oxytocin use and cesarean deliveries for labor dystocia and accordingly to avoid unnecessary iatrogenic harm to a portion of the population of women having babies.

\section{Acknowledgment}

We thank Corinne Dupont and the workgroup for their helpful advice and the reading group for the time its members took to improve this article. We also thank Jo Ann Cahn for her translation of this article. This research did not receive any specific grant from funding agencies in the public, commercial, or non-profit sectors.

\section{References}

[1] Albers LL, Schiff M, Gorwoda JG. The length of active labor in normal pregnancies. Obstet Gynecol 1996;87(3):355-9.

[2] Rouse DJ, Owen J, Hauth JC. Active-phase labor arrest: oxytocin augmentation for at least 4 hours. Obstet Gynecol 1999;93(3):323-8. 
[3] Zhang J, Troendle JF, Yancey MK. Reassessing the labor curve in nulliparous women. Am J Obstet Gynecol 2002;187(4):824-8.

[4] Neal JL, Lowe NK, Patrick TE, Cabbage LA, Corwin EJ. What is the slowest-yetnormal cervical dilation rate among nulliparous women with spontaneous labor onset? J Obstet Gynecol Neonatal Nurs 2010;39(4):361-9.

[5] Laughon SK, Branch DW, Beaver J, Zhang J. Changes in labor patterns over 50 years. Am J Obstet Gynecol 2012;206(5):419.e1-9.

[6] Blondel B, Lelong N, Kermarrec M, Goffinet F, National Coordination Group of the National Perinatal Surveys. Trends in perinatal health in France from 1995 to 2010. Results from the French National Perinatal Surveys. J Gynécologie Obstétrique Biol Reprod 2012;41(4):e1-15.

[7] Zhang J, Landy HJ, Branch DW, Burkman R, Haberman S, Gregory KD, et al. Contemporary patterns of spontaneous labor with normal neonatal outcomes. Obstet Gynecol 2010;116(6):1281-7.

[8] Cesario SK. Reevaluation of Friedman's Labor Curve: a pilot study. J Obstet Gynecol Neonatal Nurs 2004;33(6):713-22.

[9] Spong CY, Berghella V, Wenstrom KD, Mercer BM, Saade GR. Preventing the first cesarean delivery: summary of a joint Eunice Kennedy Shriver National Institute of Child Health and Human Development, Society for Maternal-Fetal Medicine, and American College of Obstetricians and Gynecologists Workshop. Obstet Gynecol 2012;120(5):1181-93. [10] Friedman E. The graphic analysis of labor. Am J Obstet Gynecol 1954;68(6):1568-75. [11] Friedman EA. Primigravid labor; a graphicostatistical analysis. Obstet Gynecol 1955;6(6):567-89.

[12] Friedman EA, Kroll BH. Computer analysis of labour progression. J Obstet Gynaecol Br Commonw 1969;76(12):1075-9.

[13] Petrikovsky B, Cohen M, Moy F, Tancer ML. Labor patterns in grand multiparas. Int J Gynaecol Obstet 1986;24(6):439-41.

[14] Zhang J, Troendle J, Grantz KL, Reddy UM. Statistical aspects of modeling the labor curve. Am J Obstet Gynecol 2015;212(6):750.e1-4.

[15] Impey L, Hobson J, O'herlihy C. Graphic analysis of actively managed labor: prospective computation of labor progress in 500 consecutive nulliparous women in spontaneous labor at term. Am J Obstet Gynecol 2000;183(2):438-43.

[16] Cohen WR, Friedman EA. Perils of the new labor management guidelines. Am J Obstet Gynecol 2015;212(4):420-7.

[17] Zaki MN, Hibbard JU, Kominiarek MA. Contemporary labor patterns and maternal age. Obstet Gynecol 2013;122(5):1018-24.

[18] Leftwich HK, Zaki MN, Wilkins I, Hibbard JU. Labor patterns in twin gestations. Am J Obstet Gynecol 2013;209(3):254.e1-5.

[19] Peisner DB, Rosen MG. Transition from latent to active labor. Obstet Gynecol 1986;68(4):448-51.

[20] Zhang J, Troendle J, Mikolajczyk R, Sundaram R, Beaver J, Fraser W. The natural history of the normal first stage of labor. Obstet Gynecol 2010;115(4):705-10.

[21] Perl FM, Hunter DJ. What cervical dilatation rate during active labour should be considered abnormal? Eur J Obstet Gynecol Reprod Biol 1992;45(2):89-92.

[22] Albers LL. The duration of labor in healthy women. J Perinatol 1999;19(2):114-9.

[23] Jones M, Larson E. Length of normal labor in women of Hispanic origin. J Midwifery Womens Health 2003;48(1):2-9. 
[24] Kilpatrick SJ, Laros RK. Characteristics of normal labor. Obstet Gynecol 1989;74(1):85-7.

[25] Sills ES, Baum JD, Ling X, Harper MM, Levy DP, Lockwood CJ. Average length of spontaneous labor in Chinese primigravidas. J Gynécologie Obstétrique Biol Reprod 1997;26(7):704-10.

[26] Incerti M, Locatelli A, Ghidini A, Ciriello E, Consonni S, Pezzullo JC. Variability in rate of cervical dilation in nulliparous women at term. Birth Berkeley Calif 2011;38(1):30-5. [27] Fraser WD, Marcoux S, Krauss I, Douglas J, Goulet C, Boulvain M. Multicenter, randomized, controlled trial of delayed pushing for nulliparous women in the second stage of labor with continuous epidural analgesia. The PEOPLE (Pushing Early or Pushing Late with Epidural) Study Group. Am J Obstet Gynecol 2000;182(5):1165-72.

[28] Fitzpatrick M, Harkin R, McQuillan K, O’Brien C, O’Connell PR, O’Herlihy C. A randomised clinical trial comparing the effects of delayed versus immediate pushing with epidural analgesia on mode of delivery and faecal continence. BJOG 2002;109(12):1359-65. [29] Vause S, Congdon HM, Thornton JG. Immediate and delayed pushing in the second stage of labour for nulliparous women with epidural analgesia: a randomised controlled trial. Br J Obstet Gynaecol 1998;105(2):186-8.

[30] Menez-Orieux C, Linet T, Philippe H-J, Boog G. Delayed versus immediate pushing in the second stage of labor for nulliparous parturients with epidural analgesia: a metaanalysis of randomized trials. J Gynécologie Obstétrique Biol Reprod 2005;34(5):440-7.

[31] Tuuli MG, Frey HA, Odibo AO, Macones GA, Cahill AG. Immediate compared with delayed pushing in the second stage of labor: a systematic review and meta-analysis. Obstet Gynecol 2012;120(3):660-8.

[32] Roberts CL, Torvaldsen S, Cameron CA, Olive E. Delayed versus early pushing in women with epidural analgesia: a systematic review and meta-analysis. BJOG 2004;111(12):1333-40.

[33] Lemos A, Amorim MMR, Dornelas de Andrade A, de Souza AI, Cabral Filho JE, Correia JB. Pushing/bearing down methods for the second stage of labour. Cochrane Database Syst Rev 2015;(10):CD009124.

[34] Cheng YW, Hopkins LM, Caughey AB. How long is too long: Does a prolonged second stage of labor in nulliparous women affect maternal and neonatal outcomes? Am J Obstet Gynecol 2004;191(3):933-8.

[35] Le Ray C, Zeitlin J, Jarreau PH, Bréart G, Goffinet F, PREMODA study group. The influence of level of care on admission to neonatal care for babies of low-risk nullipara. Eur $\mathrm{J}$ Obstet Gynecol Reprod Biol 2009;144(1):21-6.

[36] Dionne M-D, Deneux-Tharaux C, Dupont C, Basso O, Rudigoz R-C, Bouvier-Colle $\mathrm{M}-\mathrm{H}$, et al. Duration of Expulsive Efforts and Risk of Postpartum Hemorrhage in Nulliparous Women: A Population-Based Study. PloS One 2015;10(11):e0142171.

[37] Béranger R, Chantry A-A. [Recommandations pour l'administration d'oxytocine au cours du travail spontané. Chapitre 1: définition et caractéristiques du travail normal et anormal]. Rev sage-femme (2016). http://dx.doi.org/10.1016/j.sagf.2016.10.006

[38] Barasinski C, Vendittelli F. Oxytocin administration during spontaneous labor: guidelines for clinical practice. Chapter 3: interventions associated with oxytocin administration during spontaneous labor. J Gynecol Obstet Hum Reprod (2017) [This issue] [39] Fischer C. Oxytocin administration during spontaneous labor: guidelines for clinical practice. Chapter 7: epidural analgesia and use of oxytocin during spontaneous labor. $\mathrm{J}$ Gynecol Obstet Hum Reprod (2017) [This issue]

[40] Harrison MS, Ali S, Pasha O, Saleem S, Althabe F, Berrueta M, et al. A prospective population-based study of maternal, fetal, and neonatal outcomes in the setting of prolonged 
labor, obstructed labor and failure to progress in low- and middle-income countries. Reprod Health. 2015;12 Suppl 2:S9.

[41] Selin L, Wallin G, Berg M. Dystocia in labour - risk factors, management and outcome: a retrospective observational study in a Swedish setting. Acta Obstet Gynecol Scand. 2008;87(2):216-21.

[42] Dupont C, Rudigoz R-C, Cortet M, Touzet S, Colin C, Rabilloud M, et al. Frequency, causes and risk factors of postpartum haemorrhage: a population-based study in 106 French maternity units. J Gynécologie Obstétrique Biol Reprod. mars 2014;43(3):244-53.

[43] Ronel D, Wiznitzer A, Sergienko R, Zlotnik A, Sheiner E. Trends, risk factors and pregnancy outcome in women with uterine rupture. Arch Gynecol Obstet.

2012;285(2):317-21.

[44] Harper LM, Caughey AB, Roehl KA, Odibo AO, Cahill AG. Defining an abnormal first stage of labor based on maternal and neonatal outcomes. Am J Obstet Gynecol.

2014;210(6):536.e1-7.

[45] Allen VM, Baskett TF, O’Connell CM, McKeen D, Allen AC. Maternal and perinatal outcomes with increasing duration of the second stage of labor. Obstet Gynecol.

2009;113(6):1248-58.

[46] Cheng YW, Hopkins LM, Laros RK, Caughey AB. Duration of the second stage of labor in multiparous women: maternal and neonatal outcomes. Am J Obstet Gynecol. 2007;196(6):585.e1-6.

[47] Rouse DJ, Weiner SJ, Bloom SL, Varner MW, Spong CY, Ramin SM, et al. Secondstage labor duration in nulliparous women: relationship to maternal and perinatal outcomes. Am J Obstet Gynecol. 2009;201(4):357.e1-7.

[48] Le Ray C, Audibert F, Goffinet F, Fraser W. When to stop pushing: effects of duration of second-stage expulsion efforts on maternal and neonatal outcomes in nulliparous women with epidural analgesia. Am J Obstet Gynecol. 2009;201(4):361.e1-7.

[49] Gimovsky AC, Berghella V. Randomized controlled trial of prolonged second stage: extending the time limit vs usual guidelines. Am J Obstet Gynecol. 2016;214(3):361.e1-6.

[50] Tsur A, Sergienko R, Wiznitzer A, Zlotnik A, Sheiner E. Critical analysis of risk factors for shoulder dystocia. Arch Gynecol Obstet. 2012;285(5):1225-9.

[51] Mehta SH, Bujold E, Blackwell SC, Sorokin Y, Sokol RJ. Is abnormal labor associated with shoulder dystocia in nulliparous women? Am J Obstet Gynecol.

2004;190(6):1604-7; discussion 1607-9.

[52] Altman MR, Lydon-Rochelle MT. Prolonged second stage of labor and risk of adverse maternal and perinatal outcomes: a systematic review. Birth Berkeley Calif. déc

2006;33(4):315-22.

[53] Leveno KJ, Nelson DB, McIntire DD. Second-stage labor: how long is too long? Am J Obstet Gynecol. 2016;214(4):484-9.

[54] Naime-Alix A-F, Fourquet F, Sigue D, Potin J, Descriaud C, Perrotin F. [How long can we wait at full dilatation. A study of maternal and neonatal morbidity related to the duration of the second stage of labour in nulliparous women]. J Gynécologie Obstétrique Biol Reprod. 2008;37(3):268-75.

[55] Le Ray C, Fraser W, Rozenberg P, Langer B, Subtil D, Goffinet F, et al. Duration of passive and active phases of the second stage of labour and risk of severe postpartum haemorrhage in low-risk nulliparous women. Eur J Obstet Gynecol Reprod Biol.

2011;158(2):167-72. 
[56] Le Ray C, Winer N, Dreyfus M, Audibert F, Goffinet F. Neonatal issues and duration of expulsive efforts: Observationnal data in 138 French maternity units. J Gynécologie Obstétrique Biol Reprod. juin 2010;39(4):297-304.

[57] Korb D, Merazka R, Théau A, Goffinet F, Le Ray C. Maternal effects of prolonged expulsive efforts. J Gynécologie Obstétrique Biol Reprod. 2016;45(2):184-91.

[58] American College of Obstetricians and Gynecologists (College), Society for MaternalFetal Medicine, Caughey AB, Cahill AG, Guise J-M, Rouse DJ. Safe prevention of the primary cesarean delivery. Am J Obstet Gynecol. 2014;210(3):179-93.

[59] Timofeev J, Huang C-C, Singh J, Driggers RW, Landy HJ. Spontaneous labor curves in women with pregnancies complicated by diabetes. J Matern-Fetal Neonatal Med. 2012;25(1):20-6. 
Table 1. Median duration of labor from one centimeter of dilation to the next

\begin{tabular}{|c|c|c|c|}
\hline \multirow{2}{*}{$\begin{array}{l}\text { Cervical dilation } \\
\qquad(\mathrm{cm})\end{array}$} & \multicolumn{3}{|c|}{ Median duration, in hours ( $95^{\text {th }}$ percentile) } \\
\hline & $\begin{array}{c}\text { Parity } 0 \\
(\mathrm{n}=25,624)\end{array}$ & $\begin{array}{c}\text { Parity } 1 \\
(\mathrm{n}=16,755)\end{array}$ & $\begin{array}{c}\text { Parity } 2 \\
(\mathrm{n}=16,219)\end{array}$ \\
\hline $3-4 \mathrm{~cm}$ & $1.8(8.1)$ & - & - \\
\hline $4-5 \mathrm{~cm}$ & $1.3(6.4)$ & $1.4(7.3)$ & $1.4(7.0)$ \\
\hline $5-6 \mathrm{~cm}$ & $0.8(3.2)$ & $0.8(3.4)$ & $0.8(3.4)$ \\
\hline $6-7 \mathrm{~cm}$ & $0.6(2.2)$ & $0.5(1.9)$ & $0.5(1.8)$ \\
\hline $7-8 \mathrm{~cm}$ & $0.5(1.6)$ & $0.4(1.3)$ & $0.4(1.2)$ \\
\hline $8-9 \mathrm{~cm}$ & $0.5(1.4)$ & $0.3(1.0)$ & $0.3(0.9)$ \\
\hline $9-10 \mathrm{~cm}$ & $0.5(1.8)$ & $0.3(0.9)$ & $0.3(0.8)$ \\
\hline $\begin{array}{c}2^{\text {nd }} \text { stage of labor } \\
\text { (without epidural } \\
\text { analgesia) }\end{array}$ & $0.6(2.8)$ & $0.2(1.3)$ & $0.1(1.1)$ \\
\hline $\begin{array}{c}2^{\text {nd }} \text { stage of labor } \\
\text { (with epidural } \\
\text { analgesia) }\end{array}$ & $1.1(1.8)$ & $0.4(2.0)$ & $0.3(2.6)$ \\
\hline
\end{tabular}

Adapted from Zhang et al. 2010 [7]. Results based on 62,415 women from the Consortium of Safe Labor cohort (200,000 women who gave birth between 2004 and 2008 in 19 US hospitals) with all of the following characteristics: spontaneous singleton pregnancy, cephalic presentation, at term, vaginal delivery. 
Table 2. Median duration of labor in nulliparas, from different studies of the Consortium of Safe Labor cohort (2002-2008)

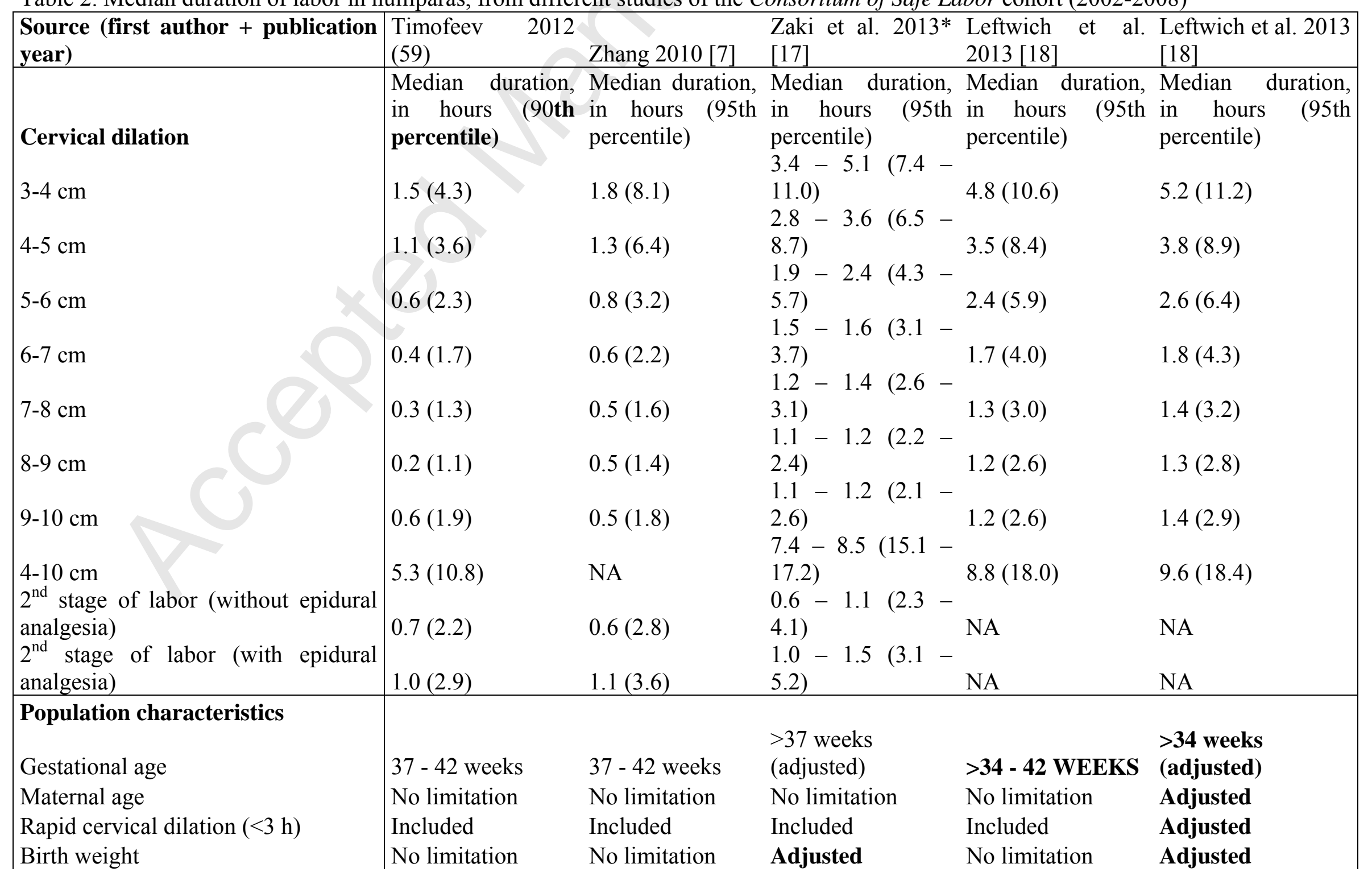




\begin{tabular}{|c|c|c|c|c|c|}
\hline Induction of labor & Exclusion & Included & Adjusted & Included & Included \\
\hline Cesarean during labor & Exclusion & Exclusion & Included & Included & Included \\
\hline Prolonged labor & Included & Included & Included & Included & Included \\
\hline Labor dystocia & Included & Included & Included & Included & Included \\
\hline
\end{tabular}

* population stratified in 4 age subgroups (maximum and minimum durations are presented when they differ). The cohort included 200,000 women who gave birth between 2004 and 2008 in 19 US hospitals.

Table 3. Median duration of labor in parous women, from different studies of the Consortium of Safe Labor cohort (2002-2008)

\begin{tabular}{|c|c|c|c|c|c|}
\hline $\begin{array}{l}\text { Source (first author }+ \text { publication } \\
\text { year) }\end{array}$ & $\begin{array}{l}\text { Timofeev } 2012 \\
(59)\end{array}$ & Zhang 2010* [7] & $\begin{array}{l}\text { Zaki et al. } 2013 * * \\
{[17]}\end{array}$ & $\begin{array}{l}\text { Leftwich et al. } \\
2013[18]\end{array}$ & $\begin{array}{l}\text { Leftwich et al. } 2013 \\
\text { [18] }\end{array}$ \\
\hline Cervical dilation & $\begin{array}{l}\text { Median duration, } \\
\text { in hours (90th } \\
\text { percentile) }\end{array}$ & $\begin{array}{l}\text { Median duration, } \\
\text { in hours (95th } \\
\text { percentile) }\end{array}$ & $\begin{array}{l}\text { Median duration, } \\
\text { in hours (95th } \\
\text { percentile) } \\
4.4-5.8(9.5-\end{array}$ & $\begin{array}{l}\text { Median duration, } \\
\text { in hours (95th } \\
\text { percentile) }\end{array}$ & $\begin{array}{l}\text { Median duration, } \\
\text { in hours (95th } \\
\text { percentile) }\end{array}$ \\
\hline $3-4 \mathrm{~cm}$ & $1.5(4.4)$ & NA & $\begin{array}{l}11.5) \\
2.7-3.9(6.2-\end{array}$ & $5.8(12.3)$ & $7.6(14.4)$ \\
\hline $4-5 \mathrm{~cm}$ & $1.0(3.5)$ & $1.4(7.0-7.3)$ & $\begin{array}{l}8.7) \\
1.8-2.0(4.5-\end{array}$ & $3.5(8.1)$ & $4.2(9.2)$ \\
\hline $5-6 \mathrm{~cm}$ & $0.5(2.2)$ & $0.8(3.4)$ & $\begin{array}{l}4.9) \\
1.3-1.6(3.5-\end{array}$ & $2.2(5.6)$ & $2.5(6.3)$ \\
\hline $6-7 \mathrm{~cm}$ & $0.3(1.4)$ & $0.5(1.8-1.9)$ & $\begin{array}{l}4.3) \\
0.8-1.0(1.8-\end{array}$ & $1.5(4.2)$ & $1.7(4.6)$ \\
\hline $7-8 \mathrm{~cm}$ & $0.1(0.9)$ & $0.4(1.2-1.3)$ & $\begin{array}{l}2.7) \\
0.8-0.9(2.1-\end{array}$ & $1.1(3.0)$ & $1.3(3.5)$ \\
\hline $8-9 \mathrm{~cm}$ & $0.1(0.6)$ & $0.3(0.9-1.0)$ & $\begin{array}{l}2.4) \\
0.6-0.9(1.4-\end{array}$ & $1.0(2.6)$ & $1.1(2.9)$ \\
\hline $9-10 \mathrm{~cm}$ & $0.2(0.9)$ & $0.3(0.8-0.9)$ & $\begin{array}{l}2.4) \\
6.5-8.8(14.1-\end{array}$ & $0.9(2.3)$ & $1.0(2.6)$ \\
\hline $\begin{array}{l}4-10 \mathrm{~cm} \\
2^{\text {nd }} \text { stage of labor (without epidural } \\
\text { analgesia) }\end{array}$ & $\begin{array}{l}3.2(8.8) \\
0.2(0.6)\end{array}$ & $\begin{array}{l}\text { NA } \\
0.1-0.2(1.1- \\
1.3)\end{array}$ & $\begin{array}{l}17.6) \\
0.2(1.0-1.3)\end{array}$ & $8.2(17.4)$ & $10.0(18.7)$ \\
\hline
\end{tabular}




\begin{tabular}{|l|lllll|}
$\begin{array}{l}2^{\text {nd }} \text { stage of labor (with epidural } \\
\text { analgesia) }\end{array}$ & $0.3(1.0)$ & $2.0)$ & $0.4-0.4(1.5-2.3)$ & NA & NA \\
\hline Population characteristics & & & & & \\
& & & WG & \\
Gestational age & $37-42 \mathrm{WG}$ & $37-42 \mathrm{WG}$ & (adjusted) & $>34$ WG & $>34$ WG (adjusted) \\
Maternal age & No limitation & No limitation & No limitation & No limitation & Adjusted \\
Rapid cervical dilation $(<3 \mathrm{~h})$ & Included & Included & Included & Included & Adjusted \\
Birth weight & No limitation & No limitation & Adjusted & No limitation & Adjusted \\
Induction of labor & Exclusion & Included & Adjusted & Included & Included \\
History of cesarean & Included & Exclusion & Exclusion & Included & Included \\
Cesarean during labor & Exclusion & Exclusion & Included & Included & Included \\
Prolonged labor & Included & Included & Included & Included & Included \\
Labor dystocia & Included & Included & Included & Included & Included \\
\hline
\end{tabular}

* population stratified according to 2 levels of parity, or ** according to 4 age groups (maximum and minimum durations are presented when they differ). The cohort included 200,000 women who gave birth between 2004 and 2008 in 19 US hospitals. 
Table 4. Summary of the principal risk factors for labor dystocia identified in the literature

\begin{tabular}{|c|c|c|c|}
\hline Risk factor & Likely & Equivocal & Unlikely \\
\hline Maternal & $\begin{array}{l}\text { - Maternal obesity; } \\
\text { - Higher maternal age; } \\
\text { - Small size; } \\
\text { - Nulliparity; } \\
\text { - Great parity; } \\
\text { - Birth spacing; } \\
\text { - Post-term pregnancy; } \\
\text { - History of } \\
\text { cesarean/dystocia; } \\
\text { - Diabetes; } \\
\text { - Hypertensive } \\
\text { disorders; } \\
\text { - Fibromas/myomas }\end{array}$ & $\begin{array}{l}\text { - Ethnicity (Asian); } \\
\text { - Lower frequency of } \\
\text { uterine contraction; } \\
\text { - Biphasic uterine } \\
\text { contraction } \\
\text {-Violence / abuse }\end{array}$ & \\
\hline Fetal & $\begin{array}{l}\text { - Higher fetal weight; } \\
\text { - Hydramnios; } \\
\text { - Deflexed and } \\
\text { posterior cephalic } \\
\text { presentation }\end{array}$ & $\begin{array}{l}\text { - gender of the } \\
\text { fetus (masculin); }\end{array}$ & - Oligoamnios; \\
\hline
\end{tabular}


Figure 1. Inclusion of articles. *Of the 283 articles considered "off-topic", 32 were excluded because they were dealt with specifically by other working groups (effect of obstetric management on dilation speed or risk of dystocia). 


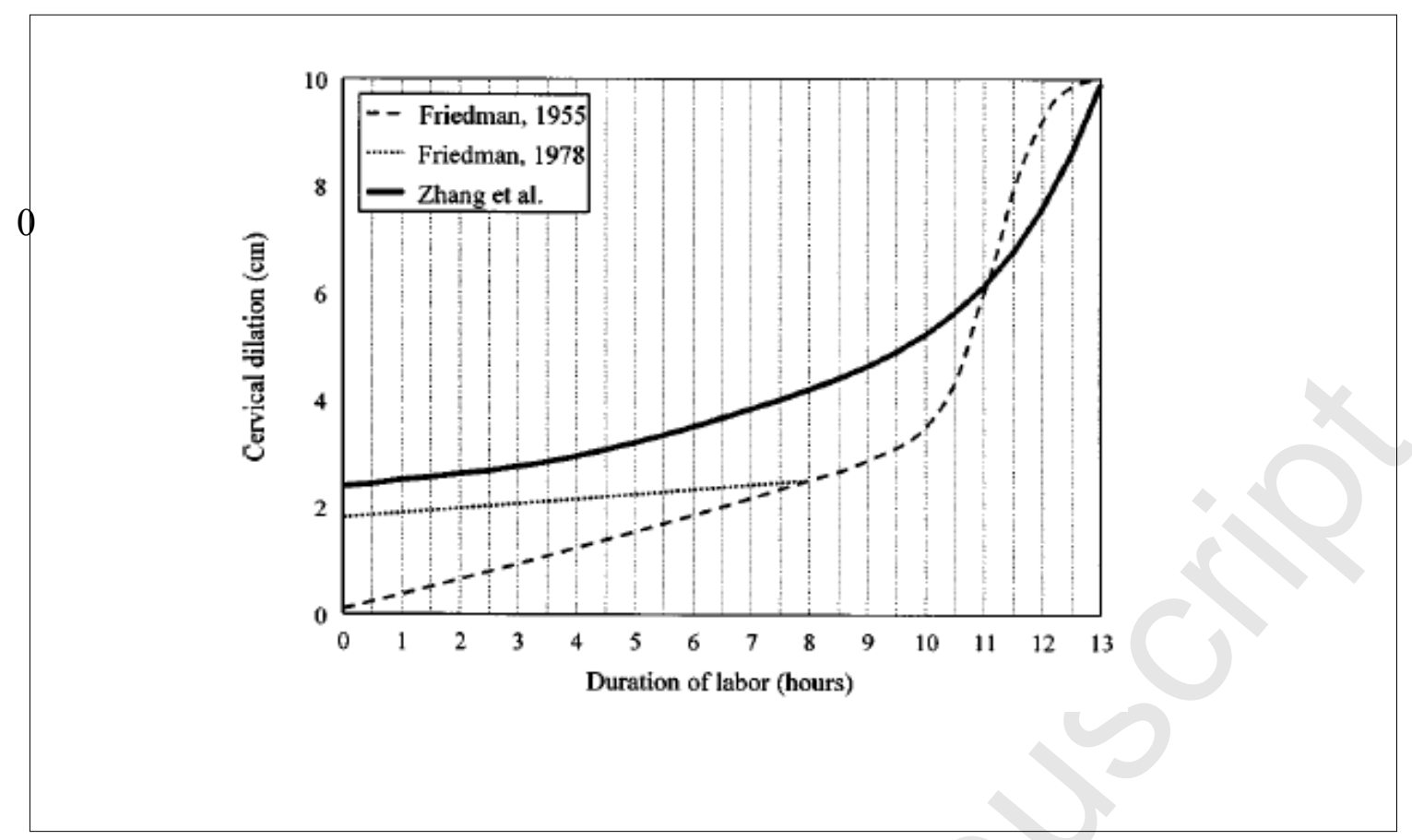

Figure 2. Comparison between the dilation curves proposed by Friedman $(1955 ; 1978)$ and by Zhang (2002). With permission of Elsevier from Zhang et al. 2002 [3]. 


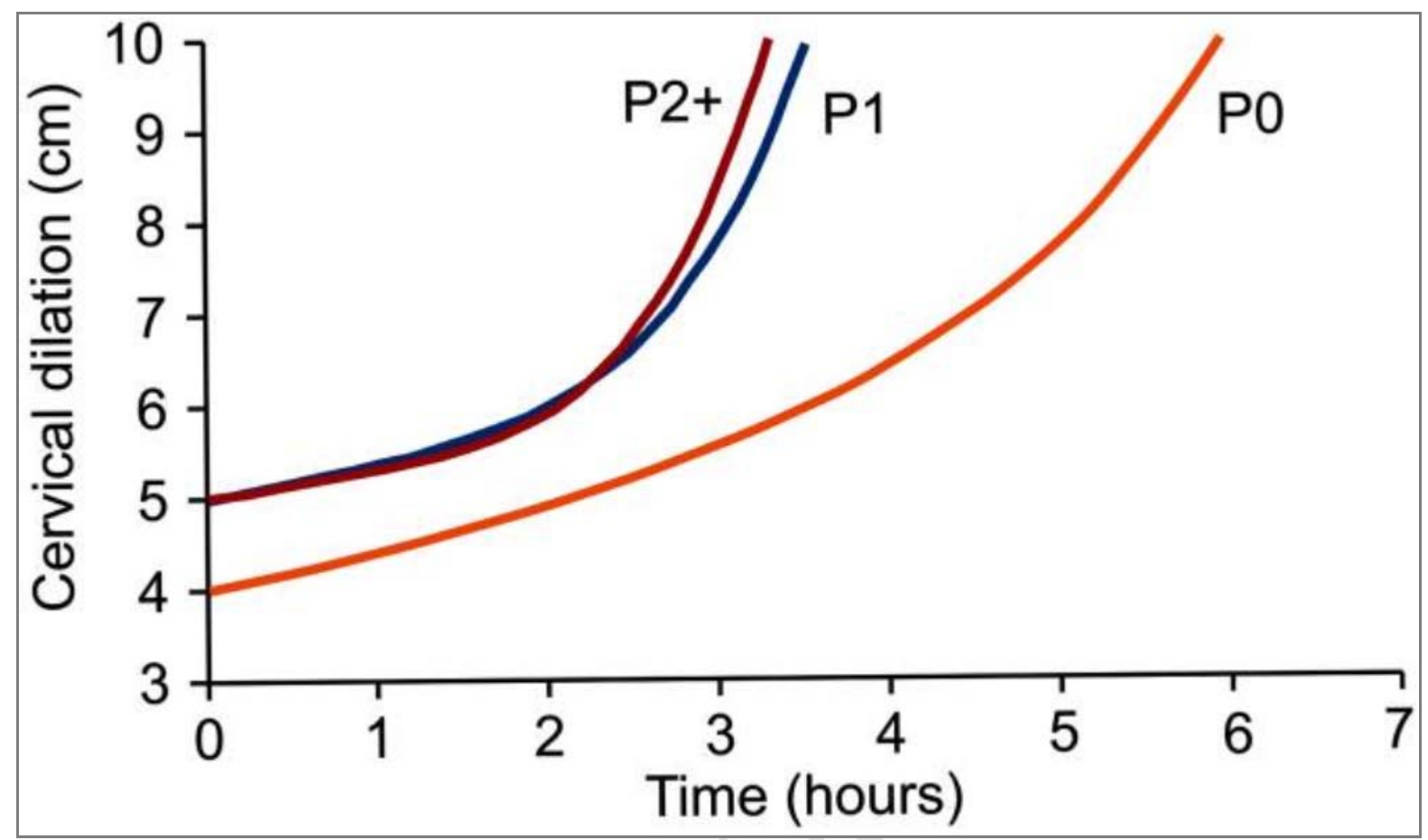

Figure 3. Zhang's dilation curves according to parity. Average labor curves based on 62,415 women from the Consortium of Safe Labor cohort (200,000 women who gave birth between 2004 and 2008 in 19 US hospitals) with all of the following characteristics: spontaneous singleton pregnancy, cephalic presentation, at term, vaginal delivery. Figure reprinted with permission of Wolters Kluwer from Zhang et al. 2010 [7]

Abbreviations: P0, nulliparous women; P1, women of parity 1; P2+, women of parity 2 or higher. 
Figure 4. Structure of labo. The normal duration of the active phase is $5.5 \mathrm{~h}$ in nulliparous women and $3 \mathrm{~h}$ in parous women (grade B). Dystocia in the first stage of labor is defined by a dilation speed $<1 \mathrm{~cm} / 4 \mathrm{~h}$ between 5 and $7 \mathrm{~cm}$ or a dilation speed $<1 \mathrm{~cm} / 2 \mathrm{~h}$ after $7 \mathrm{~cm}$ (grade B). 


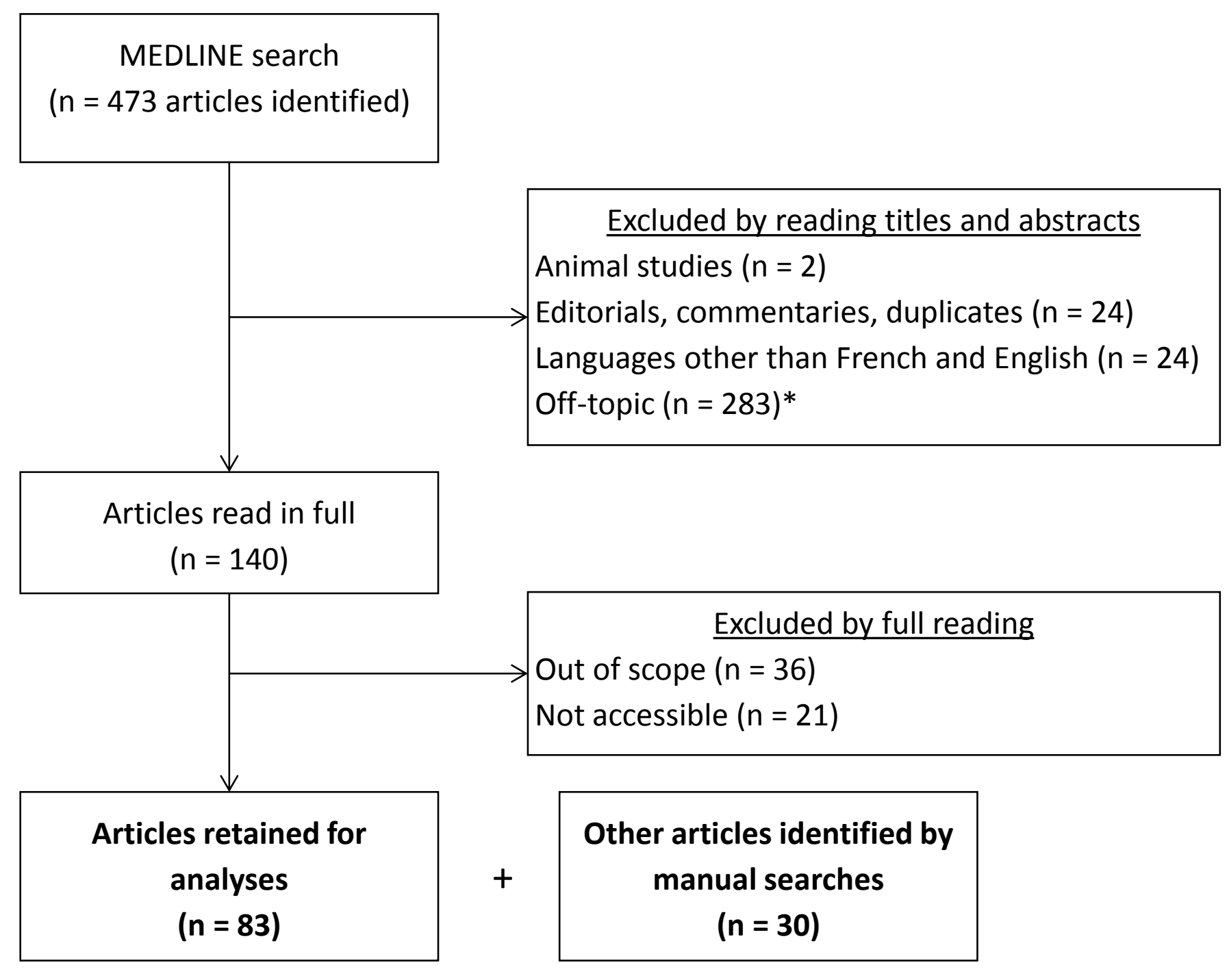




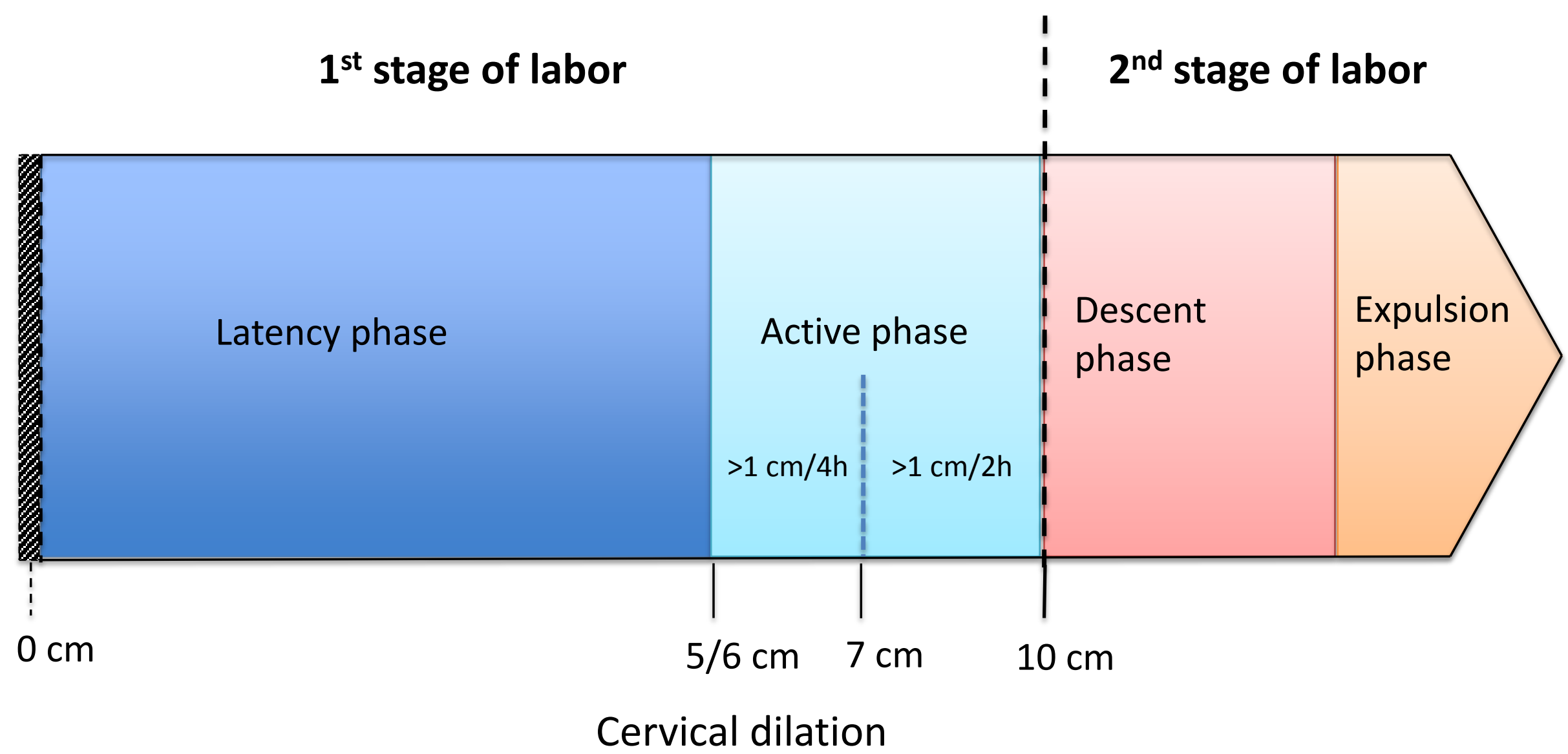

